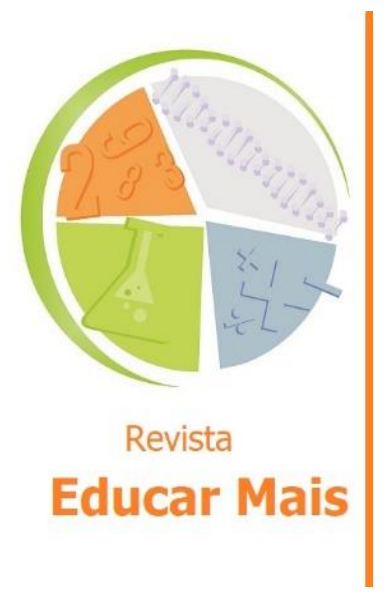

\title{
Metacognição e o estudo de língua inglesa como língua adicional: uma revisão bibliográfica
}

\section{Metacognition and the learning of English as an additional language: a bibliographic review}

\section{Metacognición y estudio del Inglés como lenguaje adicional: una revisión bibliográfica}

Amanda Zimmermann ${ }^{1}$; Gabriela Schmitt Prym Martins ${ }^{2}$; Cleci Teresinha Werner da Rosa

\section{RESUMO}

O estudo parte do entendimento da importância do uso de estratégias de aprendizagem associadas ao ensino de língua inglesa, como forma de qualificar a aprendizagem. Dentro dessas estratégias e como recorte do estudo, a investigação se ocupa de analisar as de natureza metacognitivas. Diante desse cenário, tem-se como objetivo mapear teses e dissertações associadas à presença da metacognição como recurso de aprendizagem em língua inglesa de modo a identificar as principais características. A investigação tomou como referência o banco de teses e dissertações da Capes, identificando uma tese e dez dissertações. Tais estudos são listados, descritos e analisados de modo a identificar a existência de um reduzido número de trabalhos na temática; ênfase em pesquisas empíricas de abordagem qualitativa e envolvendo; predomínio do uso de questionários como instrumento de coleta de dados; impossibilidade de identificar focos ou grupos de pesquisa; e, distribuição dos estudos por nove instruções de ensino superior e em dez programas de pós-graduação distintos. Além disso, o estudo identificou que a metacognição tem sido estudada a partir do uso de estratégias de ensino e aprendizagem.

Palavras-chave: Estratégias metacognitivas; Ensino-aprendizagem; Estado do conhecimento.

\begin{abstract}
The research bases itself in the importance of the use of learning strategies associated with the learning of English, as a way to qualify it. With these strategies and as a study cut out, the investigation is about analyzing the ones with metacognitive nature. In this scenario, the goal is to map theses and dissertations associated to the presence of metacognition as a resource of learning English in a way to identify the main features. The investigation used as reference the data bank of theses and dissertations of Capes, identifying one thesis and ten dissertations. Such researches are listed, described and analyzed in a way to identify the existence of a reduced number of work with this theme; emphasis in empiric researches of qualitative approach and involving; predominance of the usage of questionnaires as a tool for collecting data; impossibility of identifying focus or research groups; and distribution of the researches through nine Universities and in ten post-graduation different programs. Besides that, the research found that metacognition has been studied from the use of teaching-learning strategies.
\end{abstract}

Keywords: Metacognitive strategies; Teaching-learning; State of knowledge.

\footnotetext{
${ }^{1}$ Escola Sunflower, Passo Fundo/RS - Brasil

2 UPF - Universidade de Passo Fundo, Passo Fundo/RS - Brasil
} 


\section{RESUMEN}

El estudio comienza por comprender la importancia de utilizar estrategias de aprendizaje asociadas con la enseñanza del idioma inglés, como una forma de calificar el aprendizaje. Dentro de estas estrategias y como parte del estudio, la investigación se refiere al análisis de aquellos de naturaleza metacognitiva. Dado este escenario, el objetivo es mapear tesis y disertaciones asociadas con la presencia de la metacognición como recurso de aprendizaje en inglés para identificar las características principales. La investigación tomó como referencia el banco de tesis y disertaciones de Capes, identificando una tesis y diez disertaciones. Dichos estudios se enumeran, describen y analizan para identificar la existencia de un pequeño número de estudios sobre el tema; énfasis en la investigación empirica con un enfoque cualitativo e involucrado; predominio del uso de cuestionarios como instrumento de recolección de datos; incapacidad para identificar focos o grupos de investigación; y, distribución de estudios por nueve instrucciones de educación superior y en diez programas de posgrado diferentes. Además, el estudio identificó que la metacognición se ha estudiado a partir del uso de estrategias de enseñanza y aprendizaje.

Palabras clave:

Palabras clave: Estrategias metacognitivas; Enseñanza-aprendizaje; Estado del conocimiento.

\section{INTRODUÇÃO}

A problemática central do estudo decorre da percepção de que o ensino da língua inglesa se tornou um fenômeno mundial como evidenciado por Paiva (2005; 2010) e com ele os seus problemas. Para a língua representa aspecto central na divulgação de um povo, servindo, entre muitas outras coisas, para comunicar ideias e sentimentos, o que acaba por levar os seus falantes a uma maior participação social e cultural (PAIVA, 2010). Portanto, o domínio de uma língua é mais do que saber ler e compreender um idioma, mas utilizá-lo como meio de pertencimento a uma cultura.

Incluímos ao exposto que atualmente, a escola pública oferece de um a dois períodos semanais de língua inglesa, o que intensifica a dificuldade dos alunos de compreender a língua, considerando que duas horas semanais não são suficientes para um estudante ter bom progresso de aprendizagem. Tendo em vista que muitos alunos têm dificuldade na aquisição da língua adicional, são necessárias novas metodologias e estratégias didáticas para melhor aproveitamento e desenvolvimento dos estudantes. Língua Adicional é a língua que é adição às línguas já presentes no repertório do indivíduo. O termo pode ser aplicado a qualquer língua que não seja língua materna, como as línguas estrangeiras modernas, co-oficial, de herança, de acolhimento, de imigração. Nesse caso, o uso da metacognição como recurso de estrutura de pensamento pode vir a beneficiar a aprendizagem da língua inglesa a exemplo do que ocorre em outras áreas, como na resolução de problemas em Física (CHI et al., 1989), Ciências (ZOHAR; BARZILAI, 2013), Matemática (SCHOENFELD, 1987) e compreensão de textos (OTERO, 2002).

Ao olhar para a legislação nacional e seus correlatos, também é possível identificar uma preocupação com o ensino de língua inglesa. Na Base Nacional Curricular Comum (BNCC) sua presença no ensino fundamental, por exemplo, está relacionada a uma concepção e visão de mundo, tendo uma função social e política, como pode ser identificado no fragmento a seguir: 
Aprender a língua inglesa propicia a criação de novas formas de engajamento e participação dos alunos em um mundo social cada vez mais globalizado e plural, em que as fronteiras entre países e interesses pessoais, locais, regionais, nacionais e transnacionais estão cada vez mais difusas e contraditórias. Assim, o estudo da língua inglesa pode possibilitar a todos o acesso aos saberes linguísticos necessários para engajamento e participação, contribuindo para o agenciamento crítico dos estudantes e para o exercício da cidadania ativa, além de ampliar as possibilidades de interação e mobilidade, abrindo novos percursos de construção de conhecimentos e de continuidade dos estudos. É esse caráter formativo que inscreve a aprendizagem de inglês em uma perspectiva de educação linguística, consciente e crítica, na qual as dimensões pedagógicas e políticas estão intrinsecamente ligadas (BRASIL, 2017, p. 241, grifo do original).

Nesse entendimento, a escola precisa olhar mais atentamente para o processo de ensino-aprendizagem da língua inglesa, uma vez que ela possibilitará aos sujeitos uma ampliação não apenas de vocabulários em outro idioma, mas de conhecer seus próprios métodos e estratégias na hora da leitura e/ou aprendizagem da língua. Segundo Leffa (2003), para que o estudante seja autônomo, o professor deve ser autônomo, portanto para que os alunos sejam capazes de utilizar da metacognição, o professor deve induzir e influenciar seus alunos a desenvolverem um pensamento metacognitivo, regulando e monitorando sua própria aprendizagem. Uma vez que partimos do pressuposto de que o papel do professor, com base nos estudos sobre metacognição, é ser mediador da aprendizagem, consequentemente, é preciso que ele conheça seus alunos e os processos metacognitivos que eles utilizam na aprendizagem. Diante disso, pretendemos investigar as contribuições da metacognição para o ensino da língua a partir de teses e dissertações publicadas na área.

O estudo tem como questionamento central: no contexto da educação brasileira, o que revelam as pesquisas desenvolvidas no campo da metacognição associada ao processo ensino-aprendizagem em língua inglesa?

Em outras palavras temos como objetivo mapear teses e dissertações associadas à presença da metacognição como recurso vinculado a aprendizagem em língua inglesa de modo a identificar as principais características.

Para alcançar esse objetivo, estruturamos um trabalho que além da Introdução apresenta mais três seções, assim identificados: uma associada a discussões teóricas envolvendo o entendimento de metacognição e estratégias metacognitivas; outra vinculado à descrição metodológica e a constituição do corpus do estudo; e, a última destinada a discutir os estudos selecionados. Bem como identificar características desses estudos que permitam responder ao questionamento central da pesquisa. Além das seções mencionados, o estudo está integralizado pelas considerações finais que expressam o realizado e refletem sobre os resultados, apontado possibilidades para estudos futuros.

\section{METACOGNIÇÃO NO CAMPO EDUCACIONAL}

No campo educacional, estudos sobre metacognição têm encontrado dificuldades em termos de compactuar um conceito único e suficientemente amplo que englobe as diferentes associações que têm sido ligadas ao termo. A diversidade de entendimento está relacionada a diferentes componentes que são vinculados ao termo, embora haja certo consenso entorno dos componentes apontadas pelo psicólogo americano John Hurley Flavell, considerado o precursor nos estudos envolvendo metacognição. 
Sobre os diferentes entendimentos, Zohar e Barzilai (2013) e Valenzuela (2019) destacam que a busca por uma teoria metacognitiva está entre os desejos daqueles que se servem desse termo no contexto educacional, todavia, a tarefa não tem se revelado suficiente ainda em termos da promulgação dessa teoria. Por outro lado, esses mesmos autores apontam que Flavell foi o precursor nesses estudos, particularmente se referindo ao artigo First discussant 's comments: what is memory development the development of?, publicado em 1971 pelo periódico Human Development e posteriormente ao trabalho intitulado Metacognitive aspects of problem solving publicado em 1976. Nesse último o termo aparece com o seguinte entendimento: [...] conhecimento que se tem dos próprios processos e produtos cognitivos ou de qualquer outro assunto relacionado a eles, por exemplo, as propriedades relevantes para a aprendizagem de informações ou dados (FLAVELL, 1976, p. 232, tradução nossa).

A partir desse entendimento, diferentes autores vêm se servindo dessa definição e associando a ela distintos entendimentos, como o da psicóloga Ann Brown (1987, p. 66) e expresso a seguir:

A metacognição refere-se livremente ao conhecimento de um indivíduo e o controle sobre seu sistema cognitivo. Dois problemas fundamentais com o termo são: é difícil distinguir entre o que é meta e o que é cognitivo; e tem muitas raízes históricas das quais essa área de investigação desenvolveu. A confusão que segue o uso de um único termo para um problema multifacetado é o inevitável resultado de metáforas misturadas.

A partir desses dois estudos e com o intuito de detalhar tal compreensão, Rosa $(2011 ; 2014)$ passa a estabelecer uma definição que foi operacionalizada no contexto escolar por meio de uma proposta para orientar a evocação desse pensamento a partir da realização de atividades experimentais em Física. Nas palavras da autora:

Metacognição é o conhecimento que o sujeito tem sobre seu conhecimento e a capacidade de regulação dada aos processos executivos, somada ao controle e à orquestração desses mecanismos. Nesse sentido, o conceito compreende duas componentes: o conhecimento do conhecimento e o controle executivo e autorregulador (ROSA, 2014, p. 43).

Nesse entendimento fica claro a existência de duas componentes para os processos metacognitivos que são: o conhecimento do conhecimento, que representa a identificação que o aluno faz de seus conhecimentos prévios em relação ao conteúdo ou execução de uma atividade; e o controle executivo e autorregulador, em que o estudante vai além da identificação de seus conhecimentos, monitorando e supervisionando seu próprio saber.

A essas especificidades autores de diferentes áreas vem agregando novos elementos ou operacionalizando o conceito de modo a envolver novos rótulos. Dentre esses estão o de estratégias metacognitivas. Esses, segundo Livingstons (2003) são processos sequenciais que se usa para controlar as atividades cognitivas, e para garantir que um objetivo cognitivo (por exemplo, a compreensão de um texto) foi cumprida. Esses processos ajudam a regular e fiscalizar a aprendizagem, e são constituídos de planejamento e monitoramento de atividades cognitivas, bem como verificar os resultados dessas atividades.

Monereo et al. (1994), por sua vez, entende que as estratégias são comportamentos planejados utilizados para a seleção e organização de mecanismos cognitivos, afetivos e motores para enfrentar situações problemáticas, globais ou específicas, de aprendizagem. Segue o autor mencionando que essas estratégias têm uma função primária em qualquer processo de aprendizagem, cujo papel é "facilitar a assimilação da informação que chega do lado de fora ao sistema cognitivo do sujeito, que 
envolve gerenciar e monitorar a entrada, rotulagem-categorização, armazenamento, recuperação e saída de dados" (p. 4).

Pozo (1990), por sua vez, mostra que estar consciente sobre seus processos psicológicos - ativação do pensamento metacognitivo - auxilia os sujeitos a planejar suas estratégias de ação - aprendizagem - de forma mais eficaz, de modo a facilitar a aquisição e o armazenamento das informações por meio da integração das sequências de procedimentos e atividades cognitivas. Na mesma linha, Davis, Nunes e Nunes (2005), relatam que, ao fazer o uso de estratégias metacognitivas, o sujeito acionará tanto os conhecimentos já adquiridos (prévios) e relacionados aos conteúdos disciplinares, quanto suas estratégias cognitivas. Nas palavras dos autores, "torna-se um espectador de seus próprios modos de pensar e das estratégias que emprega para resolver problemas, buscando identificar como aprimorálos" (p. 211-212).

De acordo com Rosa (2014), as estratégias podem envolver operações cognitivas e metacognitivas, ajustam-se às exigências de diferentes situações e representam processos conscientes, voltados a atingir um objetivo específico. Segue a autora relatando que as estratégias cognitivas seriam aquelas que têm o objetivo de auxiliar na organização do conhecimento, como elaborar tópicos, sublinhar, estabelecer redes de conceitos entre outros; enquanto, as de natureza metacognitivas estariam envolvidas com o planejamento, a monitoração e a regulação do próprio pensamento.

Rosa (2014), além disso, específica que muitas pesquisas têm apontado que o uso de estratégias de aprendizagem favorece uma aprendizagem significativa, uma vez que desafia e oportuniza o estudante a construir o seu próprio conhecimento, por meio de um processo mediado pelo professor. Para a autora, as estratégias que utilizam processos metacognitivos representam um aprendizado mais rico, e "conduzem os aprendizes a entender não apenas os conhecimentos específicos, mas também os mecanismos internos que lhes permitiram a construção desses conhecimentos" (ROSA, 2014, p. 82).

Nesse campo das estratégias metacognitivas, há as relacionadas à leitura e compreensão de textos, que são entendidas como aquelas que podem favorecer aos estudantes na organização e qualificação desses processos leitores. A execução das estratégias de natureza metacognitivas aplicadas a leitura e compreensão de textos, está associada a um conjunto de ações vinculadas à aspectos de natureza cognitiva, metacognitiva e afetiva.

Solé (1998, p. 69), referindo-se a Valls (1990), menciona que uma estratégia se revela útil "para regular a atividade das pessoas, à medida que sua aplicação permite selecionar, avaliar, persistir ou abandonar determinadas ações para conseguir a meta que nos propomos". Isso requer um movimento cognitivo que, ao ser agregado aos de natureza metacognitivo, por exemplo, pode levar a qualificar a sua ação.

Em termos metacognitivos, estudos como o realizado por Ogle (1986) e Jacobowitz (1990), mostram possibilidades efetivas para sua incorporação na atividade leitora dos alunos. Nos trabalhos citados, os autores apostam em momentos de paradas e reflexão sobre o conteúdo e de controle da compreensão como aspectos fundamentais para ampliar o alcance do texto.

As discussões envolvendo o uso de estratégias metacognitivas associadas a língua inglesa são objeto de investigação deste trabalho e estão associadas ao resultado do estudo empírico relato nos próximos capítulos. Dessa forma, o capítulo que segue se ocupa de apresentar o modo com os estudos selecionados foram mapeados junto ao banco de dados e, na sequência descreve e analisa tais estudos. 


\section{METODOLOGIA}

O presente estudo se apoia na abordagem qualitativa em termos da natureza e o aprofundamento do problema de pesquisa. Para Triviños (1994) essa abordagem refere-se aos procedimentos metodológicos adotados para a coleta e tratamento dos dados que busca compreender características apresentadas pelo objeto de estudo. Creswel (2007, p. 186), por sua vez, aponta que na perspectiva qualitativa, a fonte direta de dados e o pesquisador estão em seu ambiente natural, sendo a preocupação com o processo de produção dos dados maior do que com o produto. Isto é, o interesse do pesquisador está em estudar um determinado problema, verificando como ele se manifesta.

Em termos dos objetivos e os procedimentos utilizados, é possível caracterizar a pesquisa como descritiva, uma vez que se pretende descrever características de um contexto em que os dados estão presentes. Além disso, e na perspectiva de Gil (2008), o estudo desenvolvido pode ser identificado como bibliográfico, porquanto se relaciona com a busca de dados em material publicado. $\mathrm{O}$ autor ainda menciona que esse tipo de pesquisa é realizada por quase a totalidade das investigações científicas, uma vez que ela representa o começo de um processo investigatório. Por outro lado, há pesquisas, como é o caso do presente estudo, que são desenvolvidas unicamente a partir de fontes bibliográficas, caracterizando-se como uma pesquisa bibliográfica associada ao que Romanowski e Ens (2006) definem como estado do conhecimento.

As pesquisas que se ocupam com a produção do conhecimento de forma sistematizada e a partir de um campo do conhecimento, revisando estudos, são entendidas como estado do conhecimento, conforme mencionado anteriormente. De acordo com Luna (2011, p. 87-88), o foco desse tipo de investigação está em identificar "o que já se sabe [nesse campo do conhecimento], as principais lacunas, onde se encontram os principais entraves teóricos e/ou metodológicos".

Para a constituição do corpus em uma pesquisa do tipo "estado do conhecimento" devemos tomar alguns cuidados, como assinalado na pesquisa de Romanowski (2002), dentre os quais estão a seleção do banco de dado a partir da temática em estudo; a delimitação dos descritores que direcionam as buscas; a necessidade de estabelecer parâmetros para a seleção dos materiais; o refinamento dos materiais selecionados a partir da sua leitura; e a análise, sistematização e elaboração dos resultados da pesquisa.

Tais entendimentos e cuidados levaram a selecionar o corpus de investigação do presente estudo. Para isso, recorreu-se ao Catálogo de teses e dissertações da Coordenação de Aperfeiçoamento de Pessoal de Nível Superior (Capes), disponível no endereço <https://catalogodeteses.capes.gov.br/catalogoteses/\#!/> , que é o banco de dados, na forma de repositório nacional, para este tipo de produção acadêmica. Os descritores utilizados para localizar os estudos foram os seguintes: "língua inglesa" AND "metacognição".

A busca foi realizada sem recorte temporal e sem definição de áreas e subáreas de avaliação, sendo obtido onze ocorrências (uma tese e dez dissertações). Dessas, foram localizados dez trabalhos (uma tese e nove dissertações, consulta realizada em 11 de agosto de 2019 e confirmada em 14 de setembro de 2019), que foram selecionados para investigação a partir da leitura de seus resumos. $O$ universo de estudo está listado no Quadro 1 a seguir: 
Quadro 1: Relação das teses e dissertações selecionados como objeto de estudo.

\begin{tabular}{|c|c|c|c|c|c|c|}
\hline No & Título & Autor(a) & Ano & Produção & $\begin{array}{c}\text { Programa de } \\
\text { pós- } \\
\text { graduação }\end{array}$ & Instituição \\
\hline 1 & $\begin{array}{llr}\text { Aquisição da língua } \\
\text { estrangeira: um estudo } \\
\text { empírico sobre estratégias de } \\
\text { comunicação }\end{array}$ & $\begin{array}{c}\text { Eliane } \\
\text { Cavalheiro }\end{array}$ & 2004 & Dissertação & $\begin{array}{l}\text { Estudos } \\
\text { Linguísticos }\end{array}$ & $\begin{array}{l}\text { Universidade } \\
\text { Federal do } \\
\text { Paraná }\end{array}$ \\
\hline 2 & $\begin{array}{l}\text { Uma concepção alternativa de } \\
\text { educação formal aplicada ao } \\
\text { Ensino de Pronúncia de Inglês }\end{array}$ & $\begin{array}{l}\text { Tufi Neder } \\
\text { Neto }\end{array}$ & 2006 & Tese & $\begin{array}{l}\text { Estudos } \\
\text { Linguísticos }\end{array}$ & $\begin{array}{l}\text { Universidade } \\
\text { Federal de } \\
\text { Minas Gerais }\end{array}$ \\
\hline 3 & $\begin{array}{l}\text { Performance na língua inglesa } \\
\text { e sua relação com } \\
\text { procedimentos } \\
\text { metacognitivos: um estudo } \\
\text { descritivo-comparativo com } \\
\text { adolescentes de alto e baixo } \\
\text { desempenho }\end{array}$ & $\begin{array}{c}\text { Willames de } \\
\text { Andrade Graça }\end{array}$ & 2009 & Dissertação & $\begin{array}{l}\text { Cognição e } \\
\text { Linguagem }\end{array}$ & $\begin{array}{l}\text { Universidade } \\
\text { Estadual } \\
\text { Fluminense } \\
\text { Darcy } \\
\text { Ribeiro }\end{array}$ \\
\hline 4 & $\begin{array}{l}\text { Aprendizagem de língua } \\
\text { estrangeira a partir do gênero } \\
\text { carta de solicitação de } \\
\text { emprego }\end{array}$ & $\begin{array}{c}\text { Denise } \\
\text { Marques } \\
\text { Lameiras Vaz }\end{array}$ & 2010 & Dissertação & $\begin{array}{l}\text { Linguística } \\
\text { Aplicada }\end{array}$ & $\begin{array}{l}\text { Universidade } \\
\text { de Taubaté }\end{array}$ \\
\hline 5 & $\begin{array}{l}\text { Ensino de língua estrangeira: } \\
\text { uma proposta de ensino } \\
\text { integrada com o uso das } \\
\text { tecnologias da informação e da } \\
\text { comunicação com vistas ao } \\
\text { desenvolvimento } \\
\text { autonomia dos aprendizes }\end{array}$ & $\begin{array}{c}\text { Francisco Alan } \\
\text { da Silva }\end{array}$ & 2011 & Dissertação & $\begin{array}{l}\text { Estudos da } \\
\text { Linguagem }\end{array}$ & $\begin{array}{l}\text { Universidade } \\
\text { Federal do } \\
\text { Rio Grande } \\
\text { do Norte }\end{array}$ \\
\hline 6 & $\begin{array}{l}\text { Metacognição e autonomia } \\
\text { como aliadas do processo de } \\
\text { ensino e aprendizagem de } \\
\text { língua inglesa }\end{array}$ & $\begin{array}{c}\text { Ádini Leite } \\
\text { Nunes Thürck }\end{array}$ & 2012 & Dissertação & Letras & $\begin{array}{l}\text { Universidade } \\
\text { Federal de } \\
\text { Viçosa }\end{array}$ \\
\hline 7 & $\begin{array}{l}\text { Uso de estratégias } \\
\text { metacognitivas de leitura em } \\
\text { alunos da disciplina de inglês } \\
\text { instrumental }\end{array}$ & $\begin{array}{c}\text { Simara Cristina } \\
\text { e Braatz }\end{array}$ & 2012 & Dissertação & Educação & $\begin{array}{l}\text { Universidade } \\
\text { Federal do } \\
\text { Paraná }\end{array}$ \\
\hline 8 & $\begin{array}{l}\text { O desenvolvimento da } \\
\text { competência leitora em um } \\
\text { curso de inglês instrumental }\end{array}$ & $\begin{array}{c}\text { Francimaria do } \\
\text { Nascimento } \\
\text { Machado }\end{array}$ & 2014 & Dissertação & Letras & $\begin{array}{l}\text { Universidade } \\
\text { Federal do } \\
\text { Piauí }\end{array}$ \\
\hline 9 & $\begin{array}{l}\text { Espelho, espelho meu: o } \\
\text { reflexo das crenças de bons } \\
\text { aprendizes de inglês em suas } \\
\text { ações }\end{array}$ & $\begin{array}{l}\text { Marcelo } \\
\text { Carmozini }\end{array}$ & 2014 & Dissertação & $\begin{array}{l}\text { Linguística } \\
\text { Aplicada }\end{array}$ & $\begin{array}{c}\text { Universidade } \\
\text { de Brasília }\end{array}$ \\
\hline 10 & $\begin{array}{l}\text { Atividades de leitura e seus } \\
\text { objetivos em livros didáticos de } \\
\text { língua estrangeira } \\
\text { contribuições para } \\
\text { letramento crítico }\end{array}$ & $\begin{array}{c}\text { Camila } \\
\text { Carneiro } \\
\text { Pessoa Lemos }\end{array}$ & 2017 & Dissertação & $\begin{array}{l}\text { Linguística } \\
\text { Aplicada }\end{array}$ & $\begin{array}{l}\text { Universidade } \\
\text { Federal do } \\
\text { Rio de } \\
\text { Janeiro }\end{array}$ \\
\hline
\end{tabular}

Fonte: Autores (2019).

O revelado pelo quadro ilustra que a metacognição relacionada a língua inglesa tem sido mais enfatiza em dissertações que teses. Além disso, o quadro aponta que não é possível identificar focos ou grupos 
de pesquisa, uma vez que os estudos estão distribuídos por nove instruções de ensino superior e em dez programas de pós-graduação distintos.

\section{DISCUSSÃO DOS DADOS}

Esta seção se ocupa de explicitar os resultados do estudo na forma de descrição das investigações realizadas, particularmente evidenciadas pelo contexto, objetivo e resultados alcançados. Na sequência dessa descrição, apresentar-se-ão as características gerais dos estudos de modo a envolver aspectos que auxiliam na busca por responder ao questionamento central da presente pesquisa.

\subsection{Descrição dos estudos investigados}

O primeiro estudo refere-se à dissertação de Cavalheiro (2004), que está caracterizada como um estudo de caso que apresenta como objetivo principal identificar estratégias de comunicação utilizadas por aprendizes de nível pré-intermediário da língua inglesa, quando estão desenvolvendo uma atividade comunicativa oral. O estudo toma como questionamento central a seguinte pergunta: como as estratégias de comunicação podem ajudar o aluno a alcançar o progresso, realização e sucesso na aprendizagem de língua estrangeira? As estratégias de comunicação utilizadas foram comparadas com as estratégias já existentes na literatura, particularmente, com os trabalhos de Tarone (1981). O autor destaca que as estratégias comunicativas, assim como as de produção, pertencem às estratégias da língua. As comunicativas, foco do estudo, são entendidas como relacionadas

com os problemas de comunicação que surgem durante uma interação. Uma estratégia de aprendizagem de língua é uma tentativa de desenvolver competência linguística e sociolinguística na língua alvo, e.g., memorização, iniciar conversa com falante nativo e inferência (p. 18).

Como sujeito, o estudo selecionou um grupo de 23 alunos que estavam cursando o nível 4 de um curso de inglês - nível intermediário, no Centro Federal de Educação Tecnológica - CEFET, em Curitiba, PR. Participaram do estudo alunos dos cursos de Engenharia, Tecnologia, Ensino Médio e da Comunidade Externa. Os registros foram coletados por meio de dois questionários: um elaborado pela autora e que buscava características do perfil dos participantes; e, o segundo, intitulado de "Estratégias Comunicativas" apresentava como objetivo identificar e reconhecer as estratégias comunicativas usadas pelos participantes.

A metacognição no estudo esteve atrelada à dificuldade na compreensão e, então, relacionada à dificuldade no uso das estratégias comunicativas.

O estudo apontou que o processo de aprendizagem da língua adicional pode ser considerado como uma das habilidades mais complexas, pois envolve variações cognitivas. Ainda, a investigação aceita que os participantes utilizam as estratégias de comunicação sem ter a consciência do fato. Em resultado, o incentivo e instrução das estratégias de comunicação aos alunos servirão de ferramenta para melhor e mais dinâmica aprendizagem.

A tese elaborada por Neder Neto (2006) parte da necessidade de apresentar uma concepção alternativa de educação formal para o ensino da pronúncia de inglês. De forma mais específica, o estudo esteve atrelado ao ensino de pronúncia e de uma concepção alternativa de educação formal, que deram origem a uma proposta didática aplicada à estudantes do Ensino Médio. Para a elaboração dessa nova concepção, o autor recorre a estudos na área da filosofia e psicologia cognitiva, enfocando a 
responsabilidade e conscientização do aluno acerca de seu processo de aprendizagem. $\mathrm{O}$ aluno, ao ser levado a refletir sobre o processo de aprendizagem, analisa suas crenças no campo atitudinal, procedimental e conceitual, porque essa "reflexão propiciaria um movimento de reestruturação cognitiva, o qual conduziria o aluno a um estado ideal para agir com maior eficácia sobre sua aprendizagem. Nesse processo, destaca-se o desenvolvimento da autorregulação por meio do enfoque em habilidades metacognitivas" (p. 6).

A metacognição foi entendida no estudo como uma

reflexão intencional sobre si mesmo e a própria aprendizagem com vistas a uma transformação interior, envolvendo a análise dos processos mentais que lhe são inerentes e o planejamento, o monitoramento e a avaliação de seu desenvolvimento em direção à universalidade do conhecimento (p. 91).

Além disso, o autor infere a existência de uma metacognição heterônoma entendida como "a última etapa da aprendizagem para a autonomia. O aluno aprende a conduzir seu crescimento de maneira independente e a avaliar o resultado de suas ações. Quando ele for capaz disso, podemos dizer que ele alcançou a metacognição autônoma" (p. 92).

Tais entendimentos são articulados na nova concepção de ensino à pronúncia do inglês e foi elaborada a partir dos resultados identificados na pesquisa bibliográfica e na entrevista com os professores. A pesquisa foi desenvolvida na aplicação dessa nova concepção ao ensino da pronúncia com 178 alunos de um colégio da rede particular de Belo Horizonte (BH/MG). Os estudantes expressaram suas reações e opiniões acerca da eficácia dessa nova abordagem em educação. Os resultados, de acordo com Neto (2006), forneceram um suporte empírico forte, o qual permite a projeção da aplicação dessa concepção em outros contextos - tanto de ensino de língua inglesa como de Componentes Curriculares - para que suas potencialidades e limitações sejam postas à prova.

O terceiro estudo a ser relatado foi o desenvolvido por Graça (2009) e teve como questão norteadora a seguinte pergunta: a diferença entre alto e baixo rendimento que alunos adolescentes apresentam na aprendizagem da Língua Inglesa, independentemente de sua classe social, relaciona-se a procedimentos metacognitivos de autoconhecimento e de autocontrole? Para isso, a pesquisa foi realizada com vinte e oito alunos do $9^{\circ}$ ano ( $8^{a}$ série do Ensino Fundamental). $O$ autor dividiu os estudantes em dois grupos para responder um questionário, uma entrevista individual e uma entrevista coletiva. Um grupo foi intitulado como de maior desempenho, com quatorze alunos, o outro como de menor desempenho, também com quatorze alunos, ambos os grupos com sete alunos de escola particular e sete alunos de escola pública.

Os resultados evidenciam que os alunos do grupo de maior desempenho utilizam-se mais de estratégias facilitadoras da aprendizagem do que o grupo de menor desempenho. Ainda que a comparação de aspectos isolados demonstre uma diferença pouco significativa, o grupo de alunos de maior desempenho demonstra qualidades pessoais mais pertinentes ao comportamento metacognitivo.

Ao analisar os dados, Graça (2009) percebeu que o grupo de alto desempenho apresenta características pessoais mais inclinadas ao comportamento metacognitivo, estes, acredita-se que se utilizam mais intuitivamente os procedimentos de natureza metacognitiva. Embora ambos os grupos careçam de uma reflexão mais consciente sobre os processos metacognitivos de Flavell e das competências metacognitivas ou processos de autorregulação da aprendizagem, o que facilitaria ambos os grupos em suas performances. 
Como resultado, o estudo concluiu que há relação entre aprendizagem bem-sucedida e metacognição, porém é necessário que o professor torne-se consciente e incentive a reflexão metacognitiva dos alunos.

Vaz (2010) relata um estudo que examina a aprendizagem de língua inglesa de um grupo de sete alunos do $1^{\circ}$ ano do Ensino Médio de uma escola estadual e uma escola particular no Vale do Paraíba, a partir do gênero carta de solicitação de emprego. A atividade, caracterizada como sequência didática, buscou responder aos questionamentos centrais do estudo, assim formulados: quais conhecimentos os sete alunos focais constroem ao longo do processo? Que percepções os sete alunos focais têm sobre a aprendizagem do gênero a partir da sequência didática?

Na pesquisa, as percepções dos alunos sobre o processo de aprendizagem são analisadas, juntamente com os conhecimentos construídos ao longo dessa evolução. Para isso, utiliza-se da construção social da linguagem de Vygotsky (1934; 1998) e Brasil (1998) e dos gêneros do discurso de Bakhtin (1992; 2003).

Quanto à metodologia do estudo, caracteriza-se como pesquisa-ação, envolvendo a elaboração de uma sequência didática. Os dados do estudo foram coletados utilizando dois questionários, um inicial e outro final, os quais foram analisados junto das atividades desenvolvidas em aula e produção final dos estudantes.

Como consequência, o estudo apontou que a construção social do gênero carta criou interação entre alunos e professoras, levando a concluir que a perspectiva sociointeracional da linguagem possibilita a aprendizagem de uma segunda língua.

A metacognição no estudo foi mencionada como vinculada ao desenvolvimento do processo cognitivo referenciando-se nos Parâmetros Curriculares Nacionais (BRASIL, 1996). Todavia, é preciso destacar que ao longo do texto não é mais feito referência ao termo de forma especifica, mas envolvendo aspectos como a tomada de consciência dos sujeitos sobe suas identicidades e reflexões sobre as ações, o que se aproxima dos aspectos metacognitivos.

Silva (2011) tratou em seu estudo sobre o ensino-aprendizagem de língua inglesa, baseando-se em uma Noção Expandida da Zona de Desenvolvimento Proximal (NEZDP), o qual tem como orientação a conscientização dos processos metacognitivos como meio de tornar-se autônomo na aprendizagem. Uma nova perspectiva pedagógica baseada na simbiose entre os estudos de Bruner (2002), Freire (2009) e da teoria metacognitiva constituem a fundamentação teórica do estudo.

Tendo como suporte o contexto sociocultural atual, transposto pelas Tecnologias da Informação e da Comunicação, a integração professor-aluno no processo de ensino-aprendizagem, com o apoio da internet, utilizou-se como intermédio a proposta emergente dessa perspectiva teórica. 0 objetivo do estudo foi o de preencher uma lacuna relaciona a aprendizagem como um processo que leva a autonomia, desenvolvendo uma proposta didática capaz de promover a metacognição dos aprendizes e, por messes, possibilitar a autonomia na aprendizagem.

O estudo desenvolveu-se a partir da Pesquisa-Ação Integral e Sistêmica (PAIS). Esse tipo de pesquisa busca "uma mudança projetada em sucessivas espirais ou ciclos. Ela busca explicar e compreender a prática por meio da implementação dos próprios sujeitos participantes da pesquisa, objetivando a sua progressão" (p. 30). O estudo voltado a ações didáticas na forma de plenárias (cinco ao total) sobre o conteúdo foi pautado em reflexões metacognitivas, envolvendo seis participantes, dentre eles quatro 
estudantes do Ensino Médio, a professora da turma e o pesquisador. Para coleta de dados foi utilizado o diário de bordo, videogravações e a entrevista com a professora.

Como resultado o estudo concluiu como verdadeira a hipótese de que a ampliação do conjunto de conhecimentos espontâneos dos alunos e da integração dos mesmos com o professor pode facilitar a aprendizagem de conceitos científicos, estimulando a metacognição e, assim, promovendo a autonomia. Dentre as inferências metacognitivas está a de que com o desenrolar das plenárias os estudantes foram adquirindo confiança e compreensão sobe o que deveria ser feito, o que no entender do autor é um representativo de uma mudança metacognitiva.

A sexta pesquisa a ser relatada foi a de Thürck (2012), definida como um estudo de caso, teve como objetivo investigar o conhecimento sobre metacognição e autonomia dos professores e alunos de língua inglesa, componentes do oitavo ano do Ensino Fundamental e, promover o uso dos mesmos em sala de aula. $O$ estudo parte do entendimento de que a metacognição possibilita ao aprendiz estabelecer suas metas de aprendizagem, bem como seus "objetivos, escolher estratégias, planejar o estudo, controlar o próprio desempenho, se tornando mais autônomo, o que pode levar a uma aprendizagem mais efetiva e consequentemente, a uma maior motivação" (p. 12).

A metacognição esteve atrelada à autonomia e foi aspecto central no estudo, sendo pauta de investigação junto aos professores e orientativos para as atividades desenvolvidas com os estudantes. Nesse sentido, seu entendimento foi estruturado a partir das obras de Wenden $(1987 ; 1991 ; 1999)$, Couceiro Figueira (2003) e Ribeiro (2003).

Os dados para o estudo foram coletados a partir de questionários abertos, entrevistas e um grupo focal, para mais tarde realizar um trabalho de intervenção conscientizadora, realizada a partir de atividades com foco metacognitivo e autônomas implementadas.

Como resultado, o pesquisador menciona que pode notar indícios de mudança no comportamento cognitivo dos aprendizes e em suas atitudes durante a aprendizagem, assim como uma maior conscientização do aluno relativo ao seu potencial de aprendizagem. Quanto à professora, as marcas de conscientização foram menos percebidas. Por fim, o autor acena para a necessidade de averiguar a relação entre o rendimento metacognitivo e as habilidades metacognitivas, o que no seu entender pode resultar em um importante aspecto a ser considerado no estudo de língua inglesa.

O sétimo estudo foi o desenvolvido por Braatz (2012) e teve como objetivo analisar a consciência metacognitiva das estratégias de leitura de um grupo de 19 estudantes de um curso técnico de uma instituição federal de ensino, na disciplina de Inglês Instrumental.

A pesquisa de caráter exploratório-descritiva foi realizada a partir do uso de dois questionários: um adaptado do Survey of Reading Strategies - SORS para avaliar estratégias metacognitivas e de leitura; e, um elaborado pela autora cuja natureza era informativa. O SORS é um inventário metacognitivo que associa estratégias metacognitivas às de leitura para nativos nos Estados Unidos, desenvolvido por Mokhtai e Sheorey (2002). De acordo com Braatz (2012) esse questionário tem representado uma boa confiabilidade (confiabilidade interna $=0,89$ ou melhor), para avaliação da consciência metacognitiva com não-nativos. O questionário avalia 13 estratégias de leitura globais, oito de leitura de solução de problemas e nove de suporte à leitura. $\mathrm{O}$ segundo questionário foi de natureza informativa com objetivo de levantar informações relativas à idade, nível de escolaridade, experiência com aprendizado de língua inglesa, nível de proficiência na língua inglesa. 
Os pressupostos teóricos que subsidiaram o estudo estiveram atrelados às obras de Carrel (1995), Flavell (1979; 1999), Kato (1999; 2004), Kleiman (2004; 2011), Koch e Elis (2011), Mokhtari e Sheorey (2002), Portilho (2004; 2005; 2009), entre outros como especificado pela autora. A metacognição aparece com potencializado e favorecedora da leitura a partir da tomada de consciência dos sujeitos sobre seus próprios processos de aprendizagem ou, nesse caso, de compreensão.

Os resultados do estudo apontam haver uma alta consciência metacognitiva no uso das estratégias de leitura pelos alunos participantes do estudo, com predomínio das associadas a resolução de problemas, seguida pelas estratégias gerais e, por fim, as de suporte à leitura. De forma mais geral, o estudo infere a importância "da habilidade de leitura de línguas estrangeiras, em especial nesta investigação da língua inglesa, na perspectiva da metacognição" (p. 160). Além disso, a autora menciona como continuidade da pesquisa a necessidade de verificar a relação entre a "consciência metacognitiva de estratégias de leitura e o desempenho na compreensão leitora de textos na língua inglesa como língua estrangeira com abordagem instrumental" (p. 162).

A dissertação realizada por Machado (2014) teve como objetivo analisar o uso de estratégias de leitura em textos da língua inglesa, com o intuito de refletir sobre o desenvolvimento no processo de ensinoaprendizagem dos mesmos em um curso ofertado tanto a professores quanto a alunos.

O estudo utiliza-se, na fundamentação teórica, do conceito e modelos de leitura, assim como a leitura em uma língua estrangera. A fim de relatar a teoria dos esquemas, o estudo recorreu ao modelo de leitura interativo, ao modelo de leitura descendente, as estratégias de leitura metacognitiva, as estratégias de leitura na língua adicional, a teoria sociointerativa, entre outras discussões. Dentre os autores utilizados, destacamos: Moita Lopes (1988), Dellísola (2001), Leffa (1996) na área de leitura; Carrel (1988) na teoria dos esquemas; Grabe (1993), Kintsch e van Dijk (1978), Rumelhart (1977) no modelo de leitura interativo. Além desses, a autora se apoia em Smith (1998) e Goodman (1988), para discutir os modelos de leitura descendente; Silveira (2005) sobre a metacognição e estratégias de leitura; Aebersold e Field (1997) nos tipos de esquemas; Araújo et al. (2002) para as estratégias de leitura com textos em língua estrangeira; e Rego (2008) e Morato (1988) na perspectiva da teoria sociohistórica de Lev Vygotsky (1934/1987).

Referente à metodologia de pesquisa, a autora decidiu utilizar-se da pesquisa-ação, a pesquisa bibliográfica e a pesquisa qualitativa. A retirada de dados foi feita a partir de três questionários aplicados em sala de aula e da observação dos participantes em um curso de inglês instrumental. Tais dados estruturaram reflexões dos participantes sobre suas expectativas em relação ao curso, conhecimento da língua inglesa, leitura e estratégias de leitura em uma língua adicional.

A análise final permitiu a autora perceber que muitos estudantes tinham uma grande deficiência na leitura dos textos em língua estrangeira e que isso está vinculado a vários fatores, tais como os linguísticos, não linguísticos e semânticos. Ainda que, estes alunos, se esforcem para entender os textos sem quebra de sentido, há participantes muito dependentes do detalhamento de sentido. Infere-se então que o desempenho no processo de leitura não é garantido pelo uso das estratégias de leitura.

A dissertação de Carmozini (2014) consiste num estudo de caso coletivo que teve como objetivo investigar as crenças dos bons aprendizes de Inglês Língua Estrangeira (ILE) sobre sua aprendizagem e sua própria competência gramatical e comunicativa. Nesse contexto, toma realce a metacognição, uma vez que como mencionado pelo autor "bons aprendizes são geralmente dotados de conhecimento metacognitivo, que influencia a sua aprendizagem" (p. 14). 
Para tal estudo o autor selecionou quatro alunos de nível avançado e com perfis linguísticos parecidos e crenças e estratégias diferentes em um instituto de línguas particular do Distrito Federal. Para analisar a falas desses alunos considerados com expertises no ILE, foi analisado a ocorrência de padrões de ações e comportamentos (ou estratégias de aprendizagem) que os quatro sujeitos utilizassem e sua classificação ocorreu por meio da taxonomia de Oxford (1990) e da taxonomia de O'Malley (1987).

A motivação que conduziu o autor a esse projeto baseou-se em um levantamento do "estado da arte" feito por Silva (2010), por onde foi possível observar que, até aquela ocasião, no contexto brasileiro, não havia quantidade significativa de trabalhos associados a tal temática no campo da Linguística Aplicada. De acordo com o autor, a maioria dos trabalhos sobre crenças tem contemplado a fala de professores ou aprendizes malsucedidos. Ademais, o autor chama a atenção para a fala de Barcelos (2001) ao inferir que "ir além da simples descrição de crenças, para que possamos entender as ações nas quais as crenças se espelham, por meio da observação desses comportamentos em ambientes formais e informais de aprendizagem" (p. 6).

Os instrumentos utilizados para a investigação foram a observação direta em aula, entrevistas semiestruturadas e questionários fechados. Os resultados do estudo apontam que os sujeitos com expertise apresentam relativo sucesso nas ações comunicativas e gramaticais, todavia, utilizam diferentes estratégias de aprendizagem. E, ainda, que essas estratégias estão relacionadas com aspectos pessoais e próximos a metacognição, sugerindo que a consciência metacognitiva é um elemento vinculado ao estilo de aprendizagem.

A pesquisa de Lemos (2017) teve como objetivo analisar as atividades de leituras utilizados em livros didáticos do nono ano do Ensino Fundamental, da coleção Time to Share. O foco estava em identificar a forma como as atividades propostas nos livros auxiliam os estudantes a refletirem e instituírem suas concepções intencionais acerca da construção dos significados em leitura. Como hipótese do estudo, a autora parte do entendimento de que "os leitores são afetados pelas instruções que lhes são dadas antes que a leitura seja feita, e isso caracterizará que seu processamento cognitivo e as estratégias utilizadas sejam diferentes a partir do objetivo estabelecido para a leitura" (p. 10).

O estudo partiu de uma abordagem qualitativo-quantitativo com base interpretativa. Foi analisado o livro didático de referência do estudo - Time to Share - e as atividades nele propostas. A partir dessa análise e da detecção de que tais atividades não auxiliam os estudantes na reflexão de suas concepções sobre a construção de significados a partir da leitura, foram propostas algumas atividades com intuito de servir de modelo para professores que desejam favorecer o processo de construção de significativos a partir da leitura.

Como resultados de pesquisa, o estudo aponta que a maioria das atividades didáticas oferecidas no livro didático investigado favorecem a atuação dos alunos de forma passiva, particularmente em relação as informações, o que leva a reproduzir o apresentado no texto, sem que integre os conhecimentos dos alunos àquilo que o texto fornece; o livro investigado está focado na "construção de uma consciência cidadã através da escolha de temas contemporâneos, pertinentes e análogas às práticas sociais que buscam lutar contra os discursos hegemônicos" (p. 96); o material didático analisado contempla vários textos de diferentes origens; as atividades metacognitivas presentes no livro didático se resumem a pré-leitura e a dois elementos: "a mera leitura rápida do texto para busca de informações ou a cópia-colagem de frases ou expressões trazidas pelos textos" (p. 96); apresentação de uma proposta de atividade didática associada ao uso de estratégias metacognitivas. 


\subsection{Características dos trabalhos analisados}

Para caracterizar os estudos investigados recorremos a uma classificação envolvendo dois aspectos: um associado a características gerais da pesquisa (natureza do estudo, abordagem metodológica, instrumento utilizado para coleta dos dados e nível de escolarização envolvido no estudo) e outro vinculado aos termos utilizados nas palavras-chave do estudo.

Iniciamos a apresentação pelo primeiro aspecto envolvendo as características da pesquisa que estão expressas no Quadro 2.

Quadro 2: Características das teses e dissertações selecionados como objeto de estudo.

\begin{tabular}{|c|c|c|c|c|}
\hline Estudo & $\begin{array}{l}\text { Tipo do } \\
\text { estudo }\end{array}$ & $\begin{array}{l}\text { Abordagem } \\
\text { metodológica }\end{array}$ & $\begin{array}{c}\text { Instrumento para coleta dos } \\
\text { dados }\end{array}$ & Nível de escolarização \\
\hline 1 & Empírico & Qualitativa & Dois Questionários & $\begin{array}{l}\text { Ensino Médio, Ensino } \\
\text { Superior e Comunidade }\end{array}$ \\
\hline 2 & $\begin{array}{l}\text { Bibliográfico } \\
\text { Empírico }\end{array}$ & Qualitativa & $\begin{array}{l}\text { Revisão de estudos } \\
\text { Entrevista com professores } \\
\text { Questionários com alunos } \\
\end{array}$ & Ensino Médio \\
\hline 3 & Empírico & Qualitativa & $\begin{array}{l}\text { Questionário } \\
\text { Entrevista individual } \\
\text { Entrevista coletiva }\end{array}$ & Ensino Fundamental \\
\hline 4 & Empírico & Qualitativa & $\begin{array}{l}\text { Questionários } \\
\text { Produções dos alunos }\end{array}$ & Ensino Médio \\
\hline 5 & Empírico & Qualitativa & $\begin{array}{l}\text { Diário de bordo } \\
\text { Videogravações } \\
\text { Entrevista com a professora }\end{array}$ & Ensino Médio \\
\hline 6 & Empírico & Qualitativa & $\begin{array}{l}\text { Questionários abertos } \\
\text { Entrevistas } \\
\text { Grupo focal }\end{array}$ & Ensino Fundamental \\
\hline 7 & Empírico & Qualitativa & Dois Questionários & Curso Técnico \\
\hline 8 & Empírico & Qualitativa & $\begin{array}{l}\text { Três Questionários } \\
\text { Observação participante }\end{array}$ & $\begin{array}{l}\text { Educação Básica e Ensino } \\
\text { Superior }\end{array}$ \\
\hline 9 & Empírico & Qualitativa & $\begin{array}{l}\text { Observação direta em sala de aula } \\
\text { Entrevistas semiestruturadas } \\
\text { Questionário fechado }\end{array}$ & $\begin{array}{l}\text { Escola particular de ensino } \\
\text { de idiomas }\end{array}$ \\
\hline 10 & $\begin{array}{l}\text { Bibliográfico } \\
\text { Empírico }\end{array}$ & $\begin{array}{l}\text { Qualitativa- } \\
\text { Quantitativo }\end{array}$ & Análise de livro didático & Ensino Fundamental \\
\hline
\end{tabular}

Fonte: Autores (2019).

O expresso no quadro indica que praticamente todos os estudos analisados optam por estruturar suas investigações a partir de um estudo empírico e de natureza qualitativa. Vale registrar que, embora um dos estudos tenha assinalado que sua pesquisa estava associada a natureza quantitativa, identificouse que apenas gráficos foram utilizados para expressar os itens avaliados no livro didático, objeto de estudo. Tal vinculação não se caracteriza como uma pesquisa quantitativa, uma vez que não foi utilizado análise estatística.

Os instrumentos também não variam muito e se revelam basicamente associados ao emprego de questionários, podendo estar acompanhados de outros instrumentos. O foco das investigações varia em termos do nível de escolarização, não havendo predominância por algum deles. 
Como segundo aspecto a ser investigado no mapeamento realizado nas dez pesquisas selecionadas para o presente estudo, tomaram-se as palavras-chave indicadas pelos autores e que foram adotadas como critério de seleção do trabalho para o presente estudo. Neste sentido, buscou-se analisar quais são as demais palavras-chave utilizadas pelos autores e que acompanham o termo central deste estudo, qual seja, "metacognição". Essas palavras-chave são indicativos das aproximações feitas com a metacognição nas dez pesquisas analisadas.

Para a apresentação do resultado, optou-se por utilizar o recurso da nuvem de palavras, recorrendo ao programa Word Cloud Generator, disponível no endereço <https://bit.ly/1M17p8L>. O programa desenvolvido por Jason Davies gera um gráfico digital que mostra o grau de frequência das palavras em um texto. Quanto mais a palavra é utilizada, mais chamativa é a representação dessa palavra no gráfico. A Figura 1 ilustra o resultado gerado pelo programa a partir da inserção das palavras-chave utilizadas nos estudos analisados.

Figura 1: Resultado da técnica Brainstorming aplicada às palavras-chave nos estudos analisados.

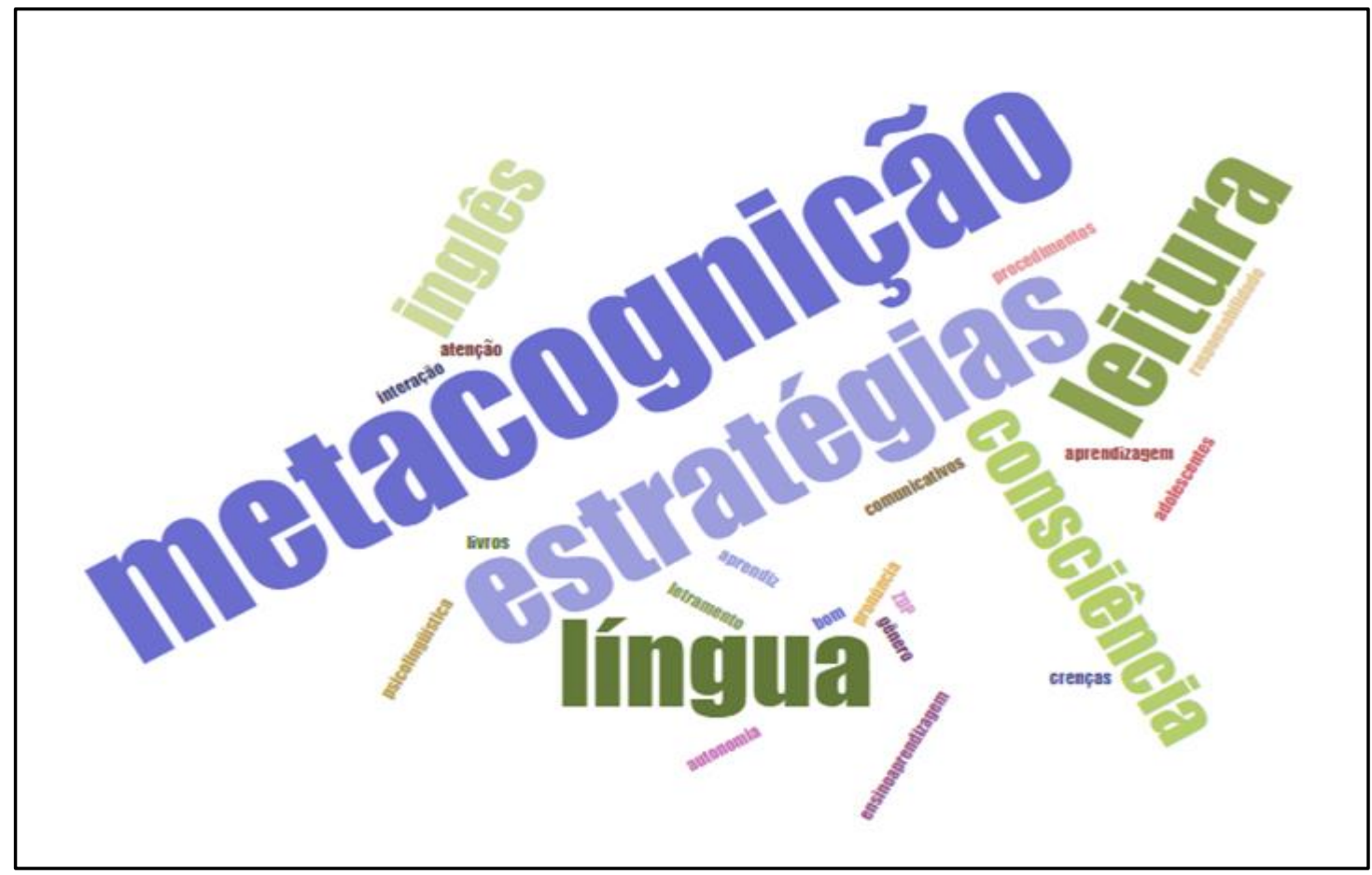

Fonte: Autores (2019).

A Figura realça as respostas obtidas em nove dos dez estudos, uma vez que a dissertação de Trürch (2012) não apresentou palavras-chave. Para a construção da figura utilizamos apenas uma palavrachave no caso de expressões. A escolha pela palavra a representar a expressar foi atribuída em função da melhor correspondência entre elas. A partir dessas considerações, temos as mais frequentes que estão destacadas na figura por tamanho e cor diferenciada. Dentre as quais destacamos: "metacognição" (6 estudos), "estratégias" de comunicação, leitura ou aprendizagem (4 estudos), "leitura" (4 estudos) e "língua" inglesa (4 estudos).

A expressão "carta de solicitação de emprego" não foi incluída por julgar não ter palavra correspondente e ter aparecido apenas em um estudo.

O resultado observado é que para as dez pesquisas analisadas, o termo "estratégia", "língua" (representando "língua inglesa") e "leitura" são as mais frequentes, evidenciando que os estudos 
relacionados estão focados em discutir o uso de estratégias metacognitivas associadas a leitura como forma de oportunizar a aprendizagem da língua inglesa.

\section{CONSIDERAÇÕES FINAIS}

O trabalho apresentado teve como preocupação central analisar a forma como a metacognição, considerado como um processo de pensamento consciente e capaz de mobilizar cognitivamente o sujeito a favor da qualificação da aprendizagem, tem servido de subsídio para as discussões envolvendo o processo de ensino e aprendizagem da língua inglesa. Para tanto, o trabalho resultante dessa investigação buscou em teses e dissertações o modo como a metacognição está relacionada ao ensino de língua inglesa.

Essa associação ocorre por meio do uso de estratégias metacognitivas que, por sua vez, estão vinculadas a uma metalinguagem, pela qual ocorrem reflexões explícitas da própria linguagem. Essa reflexão é utilizada para argumentar, explicar, analisar, estabelecer comparações e aprender a organizar o pensamento lógico. Portanto, os usos das estratégias metacognitivas tem auxiliado na compreensão da própria língua.

Essa identificação está associada as compreensões que circunscreveram os estudos analisados, evidenciando que a relação entre a metacognição e o ensino de língua inglesa ocorre a partir do uso de estratégias. Além disso e ainda por conta dos resultados, o estudo apontou a existência de um reduzido número de trabalhos na temática, uma ênfase em pesquisas empíricas associadas a abordagem qualitativa e uma predominância no uso de questionários como instrumento de coleta de dados. Outro aspecto identificado nos estudos foi o da dificuldade em identificar focos ou grupos de pesquisa preocupados com a temática no Brasil, uma vez que os trabalhos analisados estão distribuídos por nove instruções de ensino superior e em dez programas de pós-graduação distintos.

Dessa forma, o estudo realizado revela-se como uma oportunidade de refletir sobre as possibilidades de inserir a metacognição nas práticas pedagógicas no campo da língua inglesa de modo a qualificar o processo de ensino-aprendizagem e contribuir para a instituição de um novo modo de pensamento. Esse modo de pensamento relacionado a metacognição a tomada de consciência sobre os próprios conhecimentos e o constante planejamento, monitoramento e avaliação das ações executadas.

\section{REFERÊNCIAS}

BRAATZ, Simara Cristina. Uso de estratégias metacognitivas de leitura em alunos da disciplina de inglês instrumental. Dissertação (mestrado) - Universidade Federal do Paraná, Curitiba: 2012.

BRASIL. Ministério da Educação. Base Nacional Comum Curricular - Ensino Fundamental. Brasília: MEC, 2017.

BROWN, Ann L. Metacognition, executive control, self-regulation, and other more mysterious mechanisms. In: WEINERT, Franz E.; KLUWE, Rainer H. (eds.). Metacognition, motivation and understanding. Hillsdale, New Jersey: Lawrence Erlbaum Associates, 1987. p. 65-116.

CARMOZINI, Marcelo. Espelho, espelho meu: o reflexo das crenças de bons aprendizes de inglês em suas ações. Dissertação (mestrado) - Universidade de Brasília, Brasília: 2014. 
CAVALHEIRO, Eliane. Aquisição da língua estrangeira: um estudo empírico sobre estratégias de comunicação. Dissertação (mestrado) - Universidade Federal do Paraná, Curitiba: 2004.

CHI, Michelene T.; BASSOK, Miriam; LEWIS, Matthew W.; REIMANN, Peter; GLASER, Robert. Selfexplanations: How students study and use examples in learning to solve problems. Cognitive Science, v. 13, p. 145-182, 2011.

CRESWEL, John W. Projeto de pesquisa: método qualitativo, quantitativo e misto. 2. ed. Porto Alegre: Artmed, 2007.

DAVIS, Claudia; NUNES, Marina M. R.; NUNES, Cesar A. A. Metacognição e sucesso escolar: articulando teoria e prática. Cadernos de Pesquisa, v. 35, n. 125, p. 205-230, 2005.

FLAVELL, John H. Metacognition and cognitive monitoring: a new area of cognitive - developmental inquiry. American Psychologist, v. 34, n. 10, p. 906-911, 1979.

FLAVELL, John H. Metacognitive aspects of problem solving. In: RESNICK, Lauren B. (ed.). The nature of intelligence. Hillsdale, New Jersey: Lawrence Erlbaum Associates, 1976, p. 231-236.

FLAVELL, John H.; MILLER, Patricia H.; MILLER, Scott A. Desenvolvimento cognitivo. Tradução de Cláudia Dornelles. 3. ed. Porto Alegre: Artes Médicas Sul, 1999.

GIL, Antonio Carlos. Métodos e técnicas de pesquisa social. 6. ed. São Paulo: Atlas, 2008.

GRAÇA, Willames de Andrade. Performance na língua inglesa e sua relação com procedimentos metacognitivos: um estudo descritivo-comparativo com adolescentes de alto e baixo desempenho. Dissertação (mestrado) - Universidade Estadual Fluminense Darcy Ribeiro, Rio de Janeiro: 2009.

JACOBOWITZ, Tina. AIM: a metacognitive strategy for constructing the main idea of text. Journal of Reading, v. 33, n. 8, p. 620-624, 1990.

LEFFA, Vilson J. Quando menos é mais: a autonomia na aprendizagem de línguas. In: NICOLAIDES, Christine; MOZZILLO, Isabella; PACHALSKI, Lia; MACHADO, Maristela; FERNANDES Vera (org.). 0 desenvolvimento da autonomia no ambiente de aprendizagem de línguas estrangeiras. Pelotas: UFPEL, 2003. p. 33-49.

LEMOS, Camila Carneiro Pessoa. Atividades de leitura e seus objetivos em livros didáticos de língua estrangeira: contribuições para o letramento crítico. Dissertação (mestrado) - Universidade Federal do Rio de Janeiro, Rio de Janeiro: 2017.

LIVINGSTON, Jennifer A. Metacognition: an overview. [online] Disponível em https://files.eric.ed.gov/fulltext/ED474273.pdf. Acesso: 10 set. 2019.

LUNA, Sergio Vasconcelos de. Planejamento de pesquisa: uma introdução. São Paulo: EDUC, 2011.

MACHADO, Francimaria do Nascimento. O desenvolvimento da competência leitora em um curso de inglês instrumental. Dissertação (mestrado) - Universidade Federal do Piauí, Belém: 2014.

MONEREO, Carles; CASTELLÓ, Monteserrat; CLARIANA, Mercè; PALMA, Monteserrat; PÉREZ CABANI, Maria Lüisa. Estratégias de enseñanza y aprendizaje: formação del professorado y aplicación em la escuela. Barcelona: Graó, 1994.

NEDER NETO, Tufi. Uma concepção alternativa de educação formal aplicada ao Ensino de Pronúncia de Inglês. Tese (doutorado) - Universidade Federal de Minas Gerais, Belo Horizonte: 2006. 
OGLE, Donna M. KWL: A teaching model that develops active reading of expository text. Reading Teacher, v. 39, n. 6, p. 564-570, 1986.

OTERO, José. Noticing and fixing difficulties while understanding science texts. In: OTERO, José; LEÓN, José A.; GRAESSER, Arthur C. (orgs.). The psychology of science text comprehension. Nev York; London: Routledge, 2002. p. 281-307.

PAIVA, Vera Lúcia Menezes de Oliveira e. Ensino de Língua inglesa, reflexões e experiências. Campinas, SP: Pontes, 2005.

PAIVA, Vera Lúcia Menezes de Oliveira e. Práticas de ensino e aprendizagem de inglês com foco na autonomia. 3. ed. Campinas, SP: Pontes, 2010.

POZO, Juan Ignacio. Estrategias de aprendizaje. In: PALACIOS, Jesus; MARCHESI ULLASTRES, Álvaro; COLL SALVADOR, César. (org.). Desarrollo psicológico y educación. v. 2. Madrid: Alianza, 1990. p. 199-221.

ROMANOWSKI, Joana Paullin. As licenciaturas no Brasil: um balanço das teses e dissertações dos anos 90. Tese (doutorado) - Universidade de São Paulo, São Paulo: 2002.

ROMANOWSKI, Joana Paullin; ENS, Romilda Teodora. As pesquisas denominadas do tipo "Estado da Arte" em educação. Revista Diálogo Educacional, v. 6, n. 19, 2006. p. 37-50, set./dez. 2006.

ROSA, Cleci Teresinha Werner da. A metacognição e as atividades experimentais no ensino de Física. Tese (doutorado) - Universidade Federal de Santa Catarina, Florianópolis: 2011.

ROSA, Cleci Teresinha Werner da. Metacognição no ensino de Física: da concepção à aplicação. Passo Fundo: Editora da Universidade de Passo Fundo, 2014.

SCHOENFELD, Alan H. What's all the fuss about metacognition?. In: SCHOENFELD, Alan H. (org.). Cognitive science and mathematics education. Hillsdale, New Jersey: Lawrence Erlbaum Associates. 1987. p. 189-215.

SILVA, Francisco Alan da. Ensino de língua estrangeira: uma proposta de ensino integrada com o uso das tecnologias da informação e da comunicação com vistas ao desenvolvimento da autonomia dos aprendizes. Dissertação (mestrado) - Universidade Federal do Rio Grande do Norte, Natal: 2011.

SOLÉ, Isabel. Estratégias de leitura. 6. ed. Porto Alegre: Artmed, 1998.

TARONE, Elaine. Some Thoughts on the Notion of Communication Strategy. Tesol Quarterly, v. 15, n. 3, p. 285-95, 1981.

THÜRCK, Ádini Leite Nunes. Metacognição e autonomia como aliadas do processo de ensino e aprendizagem de língua inglesa. Dissertação (mestrado) - Universidade Federal de Viçosa, Viçosa, MG: 2012.

TRIVIÑOS, Augusto N. S. Introdução à pesquisa em ciências sociais: a pesquisa qualitativa em educação. 4. ed. São Paulo: Atlas, 1994.

VALENZUELA, Ángel. Qué hay de nuevo em la metacogición? Educação e Pesquisa, v. 45, e187571, p. 1-20, 2019.

VAZ, Denise Marques Lameiras. Aprendizagem de língua estrangeira a partir do gênero carta de solicitação de emprego. Dissertação (mestrado) - Universidade de Taubaté, Taubaté: 2010.

ZOHAR, Anat; BARZILAI, Sarit. A review of research on metacognition in science education: current and future directions. Studies in Science Education, v. 49, n. 2, p. 121-169, 2013. 